\title{
The GENESIS 3.0 Project: a universal graphical user interface and database for research, collaboration, and education in computational neuroscience
} David Beeman*, Zhiwei Wang, Michael Edwards, Upinder Bhalla, Hugo Cornelis* and James M Bower

Address: Computational Biology Initiative, UTHSCSA, San Antonio Texas, USA

Email: Hugo Cornelis* - hugo.cornelis@gmail.com; James M Bower - bower@uthscsa.edu

* Corresponding authors

from Sixteenth Annual Computational Neuroscience Meeting: CNS*2007

Toronto, Canada. 7-12 July 2007

Published: 6 July 2007

BMC Neuroscience 2007, 8(Suppl 2):P4 doi:10.1 I86/I47I-2202-8-S2-P4

(C) 2007 Beeman et al; licensee BioMed Central Ltd.

\section{Background}

The General Neural Simulation System (GENESIS) was first released for general use in 1988 as part of the first Methods in Computational Neuroscience Meeting at the Marine Biological Laboratory in Woods Hole, Mass. Since its release 19 years ago, GENESIS has provided one of the foundations for the ongoing course in Woods Hole, as well as courses offered by the European Union, courses in Mexico, Brazil, and India and soon in Japan, At last count GENESIS has also provided support for courses in at least 49 universities around the world where it has been used both as an instruction tool in realistic modeling of the nervous system, and as a simulation based tool for neurobiological education in general. The Book of GENESIS [1], which was designed to support both computational and neurobiological instruction has sold more than 6000 copies worldwide. This substantial support for the use of GENESIS in instruction has also provided the base for extensive and growing use of this software system in biological research providing the foundation for literally hundreds of peer reviewed scientific papers.

From the outset, the design of GENESIS has been premised on the assumption that advancement in understanding neural function requires the ability to build computer models based on the actual anatomy and physiology of the neurvous system itself [2]. GENESIS was the first broad scale modeling system in computational biology to encourage modelers to continue to develop and share model features and components. At the same time, the GENESIS project was involved in proposed technological standardization efforts for testing simulation performance and sharing of neuronal models (the Rall packs and NeuroML).

\section{GENESIS 3.0 and the future}

With the growing interest and involvement of both neurobiologists and technologists in computational neuroscience, it became clear a number of years ago that it made sense to restructure and reshape the GENESIS simulator project. While version 1 of GENESIS and the upgraded version 2 were both self contained modeling systems, the decision has been made to compartmentalize the software architecture in order to ease external contributions, and even more importantly, for enhanced interfacing capabilities with other neuroscience software tools and databases. The technical motivation for this decision is easily appreciated in the context of recent general advancements in gluing languages (e.g. Swig and Python) and interfacing languages (e.g. SOAP), as well as the level of maturity of model exchange languages (e.g. NeuroML), and meta data exchange formats (e.g. BrainML). 
More specifically, the CBI (Computational Biology Initiative) simulator architecture, recently developed in our lab as the context for GENESIS 3.0 development, is an open framework that provides a general and necessary context for the GENESIS project to proceed. It will also allow the project to focus on the user needs to conceive, organize, execute, and evaluate simulations, as well as on the development of new tools to support simulation based education, collaboration, and publication. By doing so, GENESIS 3.0 will no longer include parsers, script interpreters, run time schedulers, numerical engines, or other components necessary to actually run simulations. Instead, GENESIS 3.0 is being developed with the necessary interfaces that will, in principle, allow any simulation system to use its features. At present GENESIS 3.0 is being developed in collaboration with two simulation tool development projects, "MOOSE" under development by Upinder Bhalla in Bangalore India, and "Neurospaces" under development by Hugo Cornelis in San Antonio, Texas. This poster will describe both the GENSIS 3 project, the overall structure of the CBI framework, and how these efforts support both the development of MOOSE (by Dr. Bhalla), and Neurospaces (by Dr. Cornelis).

\section{References}

I. Bower JM, Beeman D: The book of Genesis 2nd Edition. New York Springer-Verlag 1998.

2. Bower JM: Modeling the nervous system. Trends Neurosci 1992, |5:4||-4|2.
Publish with Biomed Central and every scientist can read your work free of charge

"BioMed Central will be the most significant development for disseminating the results of biomedical research in our lifetime. " Sir Paul Nurse, Cancer Research UK

Your research papers will be:

- available free of charge to the entire biomedical community

- peer reviewed and published immediately upon acceptance

- cited in PubMed and archived on PubMed Central

- yours - you keep the copyright

Submit your manuscript here:

http://www.biomedcentral.com/info/publishing_adv.asp 